[Agr. Biol. Chem., Vol. 26, No. 5. p. 316 322, 1962]

\title{
Studies on Amylolytic Enzymes Produced by Endomyces sp.
}

\author{
Part III. Hydrolysis of Starch and Glucosyl Saccharides with \\ Amyloglucosidase
}

\author{
By Yukihiko Hattori and Itsuo Takeuchi * \\ The Institute of Physical and Chemical Research, Tokyo \\ Received January 10, 1962
}

\begin{abstract}
Various saccharides were hydrolyzed with the purified amyloglucosidase of Endomyces sp. IFO 0111 .

Glucose was the only reducing product in the digest of soluble starch. The amyloglucosidase could hydrolyze starch and amylose only incompletely though it had the ability to split $a$-D- $(1 \rightarrow 6)$ bonds and hydrolyzed amylopectin and glycogen to high extents.

It hydrolyzed malto-oligosaccharides by stepwise removal of glucose units from the nonreducing end of the molecules.
\end{abstract}

As reported previously ${ }^{1)}$, an amyloglucosidase of Endomyces species IFO 0111 (hereafter to be abbreviated as $E$. sp.) was obtained as a highly purified homogeneous enzyme preparation and its general properties were revealed.

In this paper, results of experiments on the hydrolytic action of the purified amyloglucosidase of $E$. sp. on starch and other glucosyl saccharides are presented.

\section{MATERIALS AND METHODS}

\section{Materials.}

1) Substrates. Potato starch, sweet potato starch, corn starch and wheat starch were commercial products. They were washed several times with distilled water and air-dried. Glutinous nad nonglutinous rice starches were prepared by alkali immersion method. Amylose was prepared from potato starch by Schoch's method ${ }^{2}$. Its degree of polymerization was determined by periodate method $^{32}$ modified by Kobayashi et al.4) The value obtained was 830 .

* Present address : Noda Shoyu Co., Ltd., Noda, Japan.

1) Y. Hattori and I. Takeuchi, This Journal, 25, 895 (1961)

2) E.J. Wilson, Jr., T.J. Schoch and C.S. Hudson, J. Am. Chem. Soc., 65, 1380 (1943).

3) A.L. Potter and Hassid, ibid., 70, 3488 (1948).

4) T. Kobayashi and M. Kadowaki, J. Agr, Chem, Soc, Japan, 27,
Amylopectin was commercial preparation (from potato starch) of Nagase Co., Ltd. Glycogen was purchased from Wako Pure Chemicals Co. Ltd. $\beta$-Limit dextrin was prepared from potato starch as described by Maruo et $a 1 .{ }^{5)}$. $a, \beta$-Limit dextrin was prepared as follows: $1 \%$ solution of potato starch was hydrolyzed successively with sweet potato $\beta$-amylase and chrystalline Taka-amylase at $40^{\circ} \mathrm{C}$ (this procedure was repeated twice), then the dextrin was precipitated and washed with methanol and dried in vacuum.

Maltotriose-1- $\mathrm{C}^{14}$ and maltotetraose-1- $\mathrm{C}^{14}$ were generously supplied by Dr. T. Ando ${ }^{\text {) }}$ of our laboratory. Each oligosaccharide was labeled with $\mathrm{C}^{14}$ in the position 1 of the glucose moiety at the reducing end. Isomaltose and panose were generously supplied by Dr. K. Shibazaki ${ }^{\text {7) }}$ of Tohoku University.

2) Enzyme Preparations. A solution of highly purified amyloglucosidase of $E$. sp. was prepared from culture broth by means of precipitation with ammonium sulfate, treatment with rivanol, precipitation with acetone and zone electrophoresis on cellulose powder pack. The purification procedures were reported previously ${ }^{2}$. $\beta$-Amylase solution was

5) B. Maruo and T. Kobayashi, Symposia on Enzyme Chemistry, 1, 52 (1949).

6) The authors wish to thank Dr. T. Ando for the generous gift of these substrates.

7) The authors wish to thank Dr. K, Shịbazaki for the generous gift of these substrates, 
prepared from sweet potato juice as described by Maruo et al. ${ }^{5}$ Chrystalline Taka-amylase was a gift of Mr. Tagawas) of Sankyo Co. Ltd. Malt $a$-amylase solution was prepared as described by Okazaki' ${ }^{9)}$. Chrystalline bacterial $a$-amylase was purchased from Nagase Co. Ltd.

\section{Methods.}

1) Methods of Analysis. Saccharifying ${ }^{1)}$ and dextrinizing ${ }^{10)}$ amylase activities were determined as described in the preceding papers. For determination of reducing sugars a modified Somogyi's method ${ }^{11}$ (in some cases the original method ${ }^{12)}$ ) was employed. The per cent hydrolysis of polysaccharide was calculated from the concentration of reducing sugars (expressed as glucose) produced by the enzyme and the amount of original polysaccharide in the solution determined as glucose by acid hydrolysis.

2) Paper Chromatogaphy. Paper chromatography was carried out using triple ascending development technique in the solvent system of $n$-butanol-pyridine-water $(6: 4: 3)$. Aniline hydrogen phthalate reagent ${ }^{13)}$ was used for the detection of reducing sugars.

\section{EXPERIMENTALS AND RESULTS}

\section{Hydrolysis of Starch.}

A sample of $10 \mathrm{ml}$ of $5 \%$ soluble starch solution ( $\mathrm{pH} 4.8$ ) was incubated with $1 \mathrm{ml}$ of amyloglucosidase solution of E. sp. (40 units ${ }^{14)}$ of saccharifying activity per $\mathrm{ml}$ ) at $30^{\circ} \mathrm{C}$ and $0.02 \mathrm{ml}$ aliquots of digest were taken for chromatographic analysis after incubation periods of $1 / 4,1 / 2,1$ and 4 hours. Paper chromatograms of these samples show that glucose is the only reducing product at all stages of hydrolysis of starch (Fig. 1).

As it had been found that the amyloglucosidase of E. sp., when highly purified, hydrolyses soluble starch only incompletely ${ }^{2)}$, susceptibility of varieties of starch to this enzyme was examined. The starch samples employed in the experiment were potato starch, wheat starch, corn starch, nonglutinous starch, glutinous rice starch and soluble starch. A starch solution

8) The authors wish to thank Mr. T. Tagawa for the generous gift of this enzyme.

9) H. Okazaki J. Agr. Chem. Soc. Japan, 25, 224 (1951).

10) Y. Hattori, This Journal, 25, 737 (1961).

11) T. Tabuchi and T. Kobayashi, J. Agr. Chem. Soc. Japan, 28 , 171 (1954).

12) M. Somogyi, J. Biol. Chem., 195, 19 (1952)

13) S.M. Partridge, Nature, 164, 443 (1949).

14) The definition of the unit of saccharifying activity was described in this Journal, 25, 895 (1961). was prepared by dissolving $1.15 \mathrm{~g}$ of strain in $20 \mathrm{ml}$ of $1 \mathrm{~N}$ sodium hydroxide solution and by filling it up to $100 \mathrm{ml}$ after neutralization with $1 \mathrm{~N}$ hydrochloric acid. A soluble starch solution was prepared

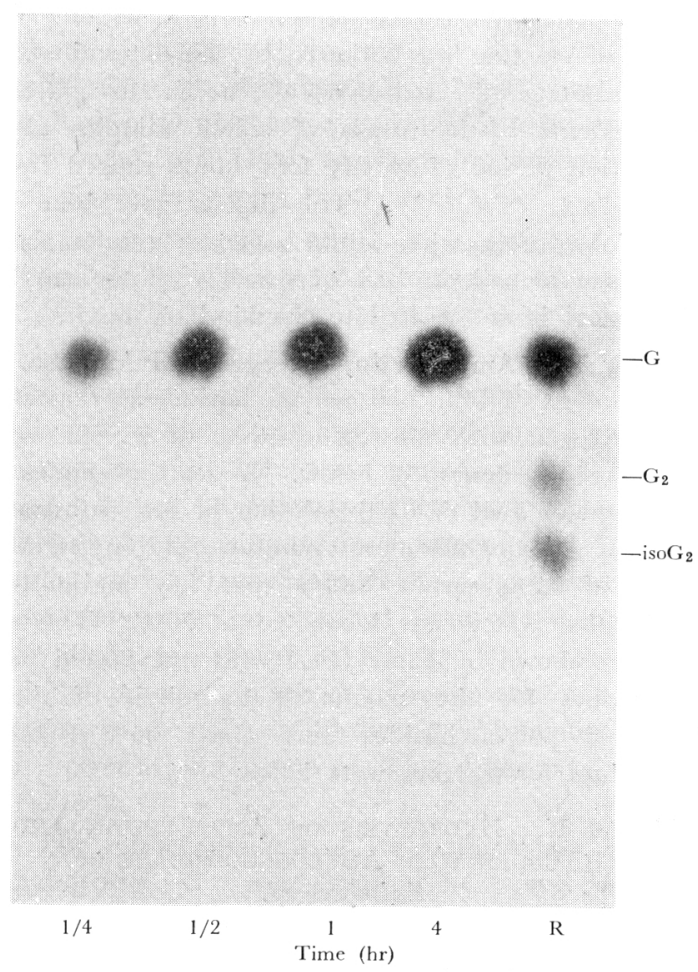

FIG. 1. A Paper Ghromatogram of the Reducing Products in Digest of Soluble Starch with Amyloglucosidase of $E$. sp.

$\mathrm{G}$, glucose; $\mathrm{G}_{2}$, maltose ; iso $\mathrm{G}_{2}$, isomaltose ; $\mathrm{R}$, reference compounds. $5 \%$ Soluble starch $10 \mathrm{ml}+$ enzyme solution $1 \mathrm{ml}$. Temperature, $30^{\circ} \mathrm{C} ; \mathrm{pH}, 4.8$.

TABLE I. HydROLYSIS OF STARCHES WITH AMYLOGLUCOSIDASE OF Endomyces sp.

\begin{tabular}{lrrrr}
\multicolumn{1}{c}{ Starch } & \multicolumn{4}{c}{ Hydrolysis (\%) } \\
& $1 \mathrm{hr}$ & $3 \mathrm{hr}$ & $6 \mathrm{hr}$ & $24 \mathrm{hr}$ \\
Potato & 65.3 & 68.0 & 74.3 & 74.4 \\
Sweet potato & 57.5 & 66.2 & 66.7 & 66.7 \\
Wheat & 63.8 & 70.1 & 77.5 & 77.9 \\
Corn & 66.5 & 72.0 & 77.2 & 77.3 \\
Nonglutinous rice & 56.0 & 65.5 & 65.9 & 67.3 \\
Glutinous rice & 54.8 & 64.4 & 74.2 & 74.3 \\
Soluble & 63.2 & 66.5 & 72.1 & 74.7
\end{tabular}

Starch (except soluble starch) was dissolved in sodium hydroxide solution and neutralized with hydrochloric acid. Final concentration of starch in the reaction mixture was $0.5 \%$. Composition of reaction mixture: see text. Temperature, $30^{\circ} \mathrm{C} ; \mathrm{pH}, 4.8$. 
by boiling without addition of alkali. 'To $10 \mathrm{ml}$ of the starch solution previously brought to $30^{\circ} \mathrm{C}, 2 \mathrm{ml}$ of the enzyme solution (30 units $/ \mathrm{ml}$ ), $5 \mathrm{ml}$ of $0.2 \mathrm{M}$ acetate buffer ( $\mathrm{pH} 4.8$ ) and $3 \mathrm{ml}$ of distilled water were added and the mixture was kept at $30^{\circ} \mathrm{C}$. The course of reaction was followed by the determination of percentage of hydrolysis of starch to glucose. The extents of hydrolysis of starch samples after incubation period of twenty four hours ranged from 67 to $78 \%$ (Table I). The digests gave blue or blue-violet color with iodine. These results show that incomplete hydrolysis of starch with the amyloglucosidase is not related to the kind of starch.

Hydrolysis of Amylopectin, Glycogen and Amylose.

Hydrolysis of branched polysaccharides amylopectin and glycogen with amyloglucosidase of $E$. sp. were conducted as described below. A reaction mixture, composed of $5 \mathrm{ml}$ of $0.5 \%$ solution of each substrate, $2 \mathrm{ml}$ of amyloglucosidase solution (40 units/ml), $2.5 \mathrm{ml}$ of $0.2 \mathrm{M}$ acetate buffer $(\mathrm{pH} 4.8)$ and $0.5 \mathrm{ml}$ of distilled water, was incubated at $30^{\circ} \mathrm{C}$. The results are shown in Table II. It was unexpected that the values for the extents of hydrolysis of these branched polysaccharides were above $95 \%$ though the values for starches were below $78 \%$.

TABLE II. HYDROLYSIS OF AMYLOPECTIN AND GLYCOGEN WITH AMYLOGLUCOSIDASE OF Endomyces sp.

Substrate Hydrolysis (\%)

$\begin{array}{lrrrr} & 1 \mathrm{hr} & 3 \mathrm{hr} & 6 \mathrm{hr} & 24 \mathrm{hr} \\ \text { Amylopectin } & 80.8 & 85.6 & 90.5 & 95.3 \\ \text { Glycogen } & 97.5 & 99.2 & 99.8 & -\end{array}$

The concentration of substrate in the reaction mixture was $0.25 \%$. Composition of reaction mixture: see text. Temperature, $30^{\circ} \mathrm{C}$; $\mathrm{pH}, 4.8$.

Hydrolysis of amylose was conducted as described by Meyer et al..$^{15)}$ Fifty $\mathrm{mg}$ of amylose dried over phosphorus pentoxide were dissolved in $2.5 \mathrm{ml}$ of $2 \mathrm{~N}$ sodium hydroxide with gentle warming and the solution was filled up to $100 \mathrm{ml}$. Four $\mathrm{ml}$ of $1 \mathrm{M}$ acetate buffer $(\mathrm{pH} \mathrm{4.8)}, 12 \mathrm{ml}$ of distilled water and $4 \mathrm{ml}$ of the amyloglucosidase solution (100 units $/ \mathrm{ml}$ ) were mixed in a beaker and brought to $35^{\circ} \mathrm{C}$. To this enzyme solution, $30 \mathrm{ml}$ of the amylose solution brought previously to $35^{\circ} \mathrm{C}$ was added dropwise and the mixture was kept at $35^{\circ} \mathrm{C}$. Values for extent of hydrolysis in the course of reaction were: $66.4 \%$ after

15) K.H. Meyer, P. Bernfeld, R.A. Boisonnes, P. Gürtler and G. Noelting, J. Phys. Colloid Chem., 53, 319 (1949). one hour, $69.2 \%$ after three hours, $71.5 \%$ after twenty four hours. The digest solution became cloudy and some precipitates appeared after the incubation. This indicates that some retrogradation occurred during the incubation. Baba et al. ${ }^{16)}$ demonstrated that sweet potato amylose was hydrolyzed completely with $a$-amylase when it was pretreated in $0.4 \mathrm{~N}$ sodium hydroxide solution at $98^{\circ} \mathrm{C}$ for one hour. According to them thirty $\mathrm{mg}$ of amylose were treated in the alkaline solution, neutralized with hydrochloric acid, buffered with acetate buffer solution ( $\mathrm{pH} 4.8$ ) and filled up to $50 \mathrm{ml}$. Twenty $\mathrm{ml}$ of this amylose solution $(0.06 \%)$ and $1 \mathrm{ml}$ of the amyloglucosidase solution $\left(100\right.$ units $/ \mathrm{ml}$ ) were mixed at $30^{\circ} \mathrm{C}$ and incubated at this temperature. Degrecs of hydrolysis in the course of reaction were: $70.1 \%$ after one hour, $72.3 \%$ after three hours, $74.5 \%$ after twenty four hours.

In a parallel experiment, $2 \mathrm{ml}$ of the same amylose solution were incubated with $1 \mathrm{ml}$ of the enzyme solution. In this case the relative concentration of enzyme was tenfold higher than that of the above described reaction mixture, but the rapid coagulation of amylose occurred on addition of enzyme and the extent of hydrolysis after twenty four hours was only $53.8 \%$.

These results indicate that the hydrolysis limit of amylose with amyloglucosidase of $E$. sp. is not raised by the alkali treatment described by Baba et al. ${ }^{16)}$. and that an extreme excess of enzyme is not favour. able for hydrolysis of amylose.

\section{Hydrolysis of Limit Dextrins.}

Five $\mathrm{ml}$ of $E$. sp. amyloglucosidase $(20$ units $/ \mathrm{ml})$ were mixed with $10 \mathrm{ml}$ of $1 \%$ solution of $\beta$ - or $a, \beta$ limit dextrin and $5 \mathrm{ml}$ of $0.2 \mathrm{M}$ acetate buffer ( $\mathrm{pH}$ 4.8 ) and the mixture was incubated at $30^{\circ} \mathrm{C}$.

As shown in Table III, amyloglucosidase of $E$. sp. had the ability to hydrolyze both $\beta$-, and $a, \beta$-limit dextrins and there were differences in the rate and

TABLE III. HYDROLYSIS OF LIMIT DEXTRINS WITH AMYLOGLUCOSIDASE OF Endomyces sp.

\begin{tabular}{lrrrr}
\multicolumn{4}{c}{ Substrate } & \multicolumn{4}{c}{ Hydrolysis (\%) } \\
& $1 \mathrm{hr}$ & $3 \mathrm{hr}$ & $6 \mathrm{hr}$ & $24 \mathrm{hr}$ \\
$\beta$-Limit dextrin & 61.0 & 64.2 & 66.8 & 74.0 \\
$\alpha, \beta$-Limit dextrin & 77.3 & 87.5 & 98.5 & -
\end{tabular}

The concentration of substrate in the reaction mixture was $0.5 \%$. Composition of reation mixture: see text. Temperature, $30^{\circ} \mathrm{C}$; $\mathrm{pH}, 4.8$.

16) A. Baba and H. Kojima, J. Agr. Chem. Soc. Japan, 32, 291 (1958). 
extent of hydrolysis of the two kinds of dextrin. From $\beta$-limit dextrin $74 \%$ of the theoretical glucose was produced in twenty four hours, whereas from $\alpha, \beta$-limit dextrin $99 \%$ of the theoretical glucose was produced in six hours.

\section{Maltase Activity.}

In a preliminary test amyloglucosidase of $E$. sp. showed maltase activity, therefore the ratio of saccharifying amylase activity to maltase activity was measured at three different steps of purification. One of them was a partially purified preparation which had not been subjected to the zone electrophoresis, the next was an amyloglucosidase fraction purified once by means of the zone electrophoresis and the third was an amyloglucosidase fraction purified by repeating the zone electrophoresis twice. Maltase activity was determined in the same way as that in the determination of saccharifying activity ${ }^{2)}$ except that the substrate, $2 \%$ soluble starch solution, was

\section{Table IV. Maltase ACtivity of Amyloglu-} COSIDASE OF Endomyces sp.

Enzyme preparation $\begin{gathered}\text { Maltase } \\ \text { activity } \\ \text { (units } / \mathrm{ml} \text { ) }\end{gathered} \quad \begin{gathered}\begin{array}{c}\text { Saccha- } \\ \text { rifying } \\ \text { activity }\end{array} \\ \text { (units } / \mathrm{ml} \text { ) }\end{gathered} \quad \mathrm{S} / \mathrm{M}^{* 4)}$
Amyloglucosidase (1)*1)
Amyloglucosidase (2)*2)

20.0
4.3
87.0
87.6
4.3
Partially purified enzyme*3)

$17.4 \quad 4.0$

$1175.0 \quad 13.5$

replaced with $2 \%$ maltose solution. One unit of the maltase activity was defined as the amount of enzyme which produces $1 \mathrm{mg}$ of glucose from maltose per $2 \mathrm{ml}$ of reaction mixture in thirty minutes.

The results are given in Table IV. The amyloglucosidase preparations purified by means of the zone electrophoresis have a saccharifying amylase/ maltase ratio of about 4 to 1 . This value is in good agreement with that reported for amyloglucosidase of Aspergillus oryzae by Okazaki ${ }^{17)}$.

\section{Action on $\mathrm{C}^{14}$-labeled Malto-oligosaccharides.}

Samples of $0.1 \mathrm{ml}$ of $0.1 \mathrm{~m}$ solution of maltotriose1- $\mathrm{C}^{14}$ and maltotetraose of $\mathrm{pH} 4.8$ were treated with $0.1 \mathrm{ml}$ of amyloglucosidase solution (10 units per $\mathrm{ml}$ ) and incubated at $30^{\circ} \mathrm{C}$. One hundredth milliliter aliquots of the digest were placed on a paper chromatogram after incubation periods of $0,1 / 4,1 / 2,1$ and 2 hours. Reaction products were separated and located by spraying with a reagent and by radioautography. Photographs of the paper chromatogram and radioautogram obtained from the maltotriose-1$\mathrm{C}^{14}$ digest are shown in Fig. 2. The radioactivities of the products in digest of maltotetraose-1- $\mathrm{C}^{14}$ were measured directly on the paper chromatogram with a Geiger-Müller counter. The values are given in Table V.

The initial products of amyloglucosidase action on maltotriose-1- $\mathrm{C}^{14}$ were maltose-1- $\mathrm{C}^{14}$ and nonradioactive glucose. This result and the values in Table $\mathrm{V}$ indicate a stepwise removal of the glucose units from the nonreducing end of the oligosaccharide molecules.

*1) Amyloglucosidase fraction purified once by zone electrophoresis.

*2) Amyloglucosidase fraction purified twice by zone clectrophoresis.

*3) Preparation just before zone electrophoresis.

*4) Ratio of saccharifying amylase activity to maltase activity.

(B)

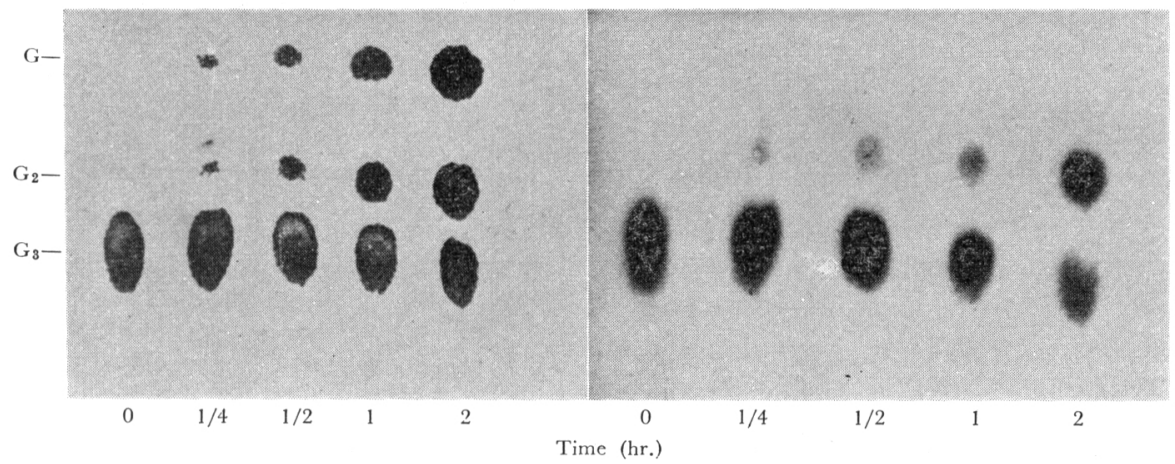

FIG. 2. A Paper Chromatogram (A) and a Radioautogram (B) of the Products in Digest oI Maltotriose-1-C 14 with Amyloglucosidase of E. sp. .

$\mathrm{G}$, glucose; $\mathrm{G}_{2}$, maltose; $\mathrm{G}_{3}$, maltotriose. Final concentration of substrate, $0.05 \mathrm{~m}$; temperature, $30^{\circ} \mathrm{C}, \mathrm{pH}, 4.8$

17) H. Okazaki, J. Agr. Chem. Soc. Japan, 28, 51 (1954). 
TABLE V. RAdioactivity OF PRODUCTS IN Digest of MaltotetraOSE-1-G ${ }^{14}$ WITH AMYLOGLUCOSIDASE OF Endomyces sp.

$\begin{array}{ccccc}\begin{array}{c}\text { Time } \\ \text { (min.) }\end{array} & \begin{array}{c}\text { Maltote- } \\ \text { traose } \\ \text { (c.p.m.) }\end{array} & \begin{array}{c}\text { Compound } \\ \text { Maltotriose }\end{array} & \text { Maltose } & \text { Glucose } \\ 0 & 1986 & 23 & 28 & 6 \\ 5 & 1660 & 348 & 24 & 11 \\ 30 & 1202 & 773 & 44 & 24 \\ 60 & 782 & 1096 & 146 & 18 \\ 120 & 114 & 1071 & 827 & 31\end{array}$

\section{Hydrolysis of Isomaltose and Panose.}

One tenth milliliter of $0.3 \mathrm{M}$ solution of isomaltose or panose buffered to $\mathrm{pH} 4.8$ was mixed with $0.1 \mathrm{ml}$ of the amyloglucosidase solution. (100 units/ml) and incubated at $30^{\circ} \mathrm{C}$. Aliquots of the digests were taken for chromatographic analysis after $0,1 / 2,1,3$ and 6-hour incubation periods.
Photographs of chromatograms of the digests are reproduced in Fig. 3. As shown in the chromatograms glucose was the hydrolysis product of both isomaltose and panose.

Joint Actions with Other Amylases on Starch.

Experiments were conducted for clarifying the effect of joint actions of Endomyces amyloglucosidase and other amylases on hydrolysis of starch. The compositions of reaction mixtures are listed in Table VI.

As shown in Fig. 4 joint action of a dextrinizing amylase and amyloglucosidase of $E$. sp. remarkably increases the rate and the extent of hydrolysis of soluble starch. The extent of hydrolysis after twenty four hour reaction was $98 \%$ in the joint action with malt $\boldsymbol{\alpha}$-amylase and $93 \%$ in the joint action with bacterial $a$-amylase, whereas the extent remained at $76 \%$ in the single action of amyloglucosidase of $E$. sp.

(B)

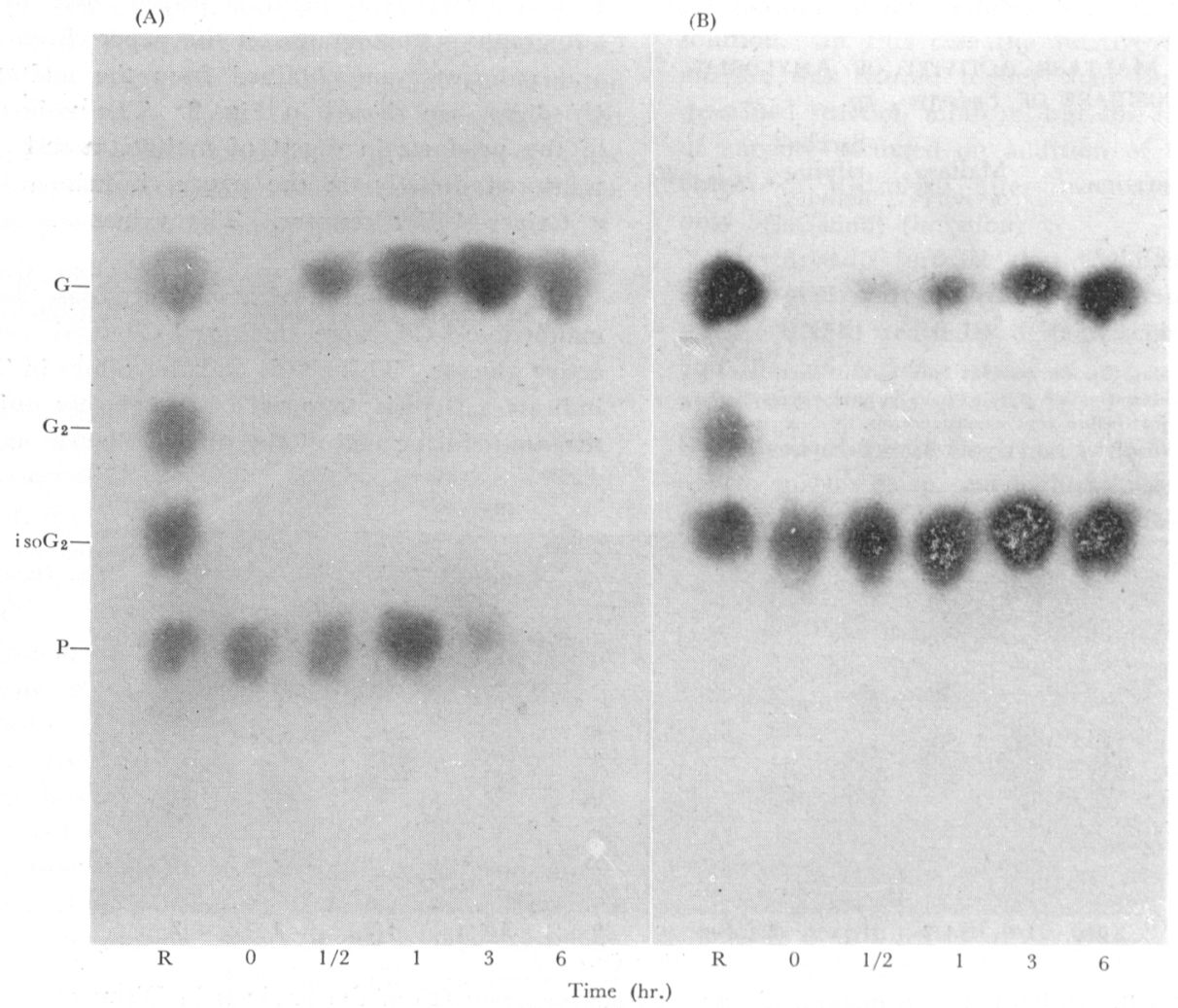

FIG. 3. Paper Chromatograms of Products in Digests of Panose (A) and Isomaltose (B) with Amyloglucosidase of $E$. sp. .

$\mathrm{G}$, glucose ; $\mathrm{G}_{2}$, maltose ; iso $\mathrm{G}_{2}$, isomaltose ; $\mathrm{P}$, panose ; $\mathrm{R}$, reference compounds. Final concentration of substrates, $0.15 \mathrm{M}$; temperature, $30^{\circ} \mathrm{C}, \mathrm{pH}, 4.8$. 
The effect of the addition of $\beta$-amylase was hardly observed.

TABLE VI. COMPOSITION OF REACTION MIXTURES IN JOINT ACTIONS

Exp. no.

\section{Component}

$2 \%$ Soluble starch solution $\underset{(\mathrm{ml})}{1} \underset{(\mathrm{ml})}{2} \stackrel{3}{(\mathrm{ml})} \quad \stackrel{4}{(\mathrm{ml})}$

Endomyces amyloglucosidase*1)

Malt $\alpha$-amylase*2)

Bacterial $\alpha$-amylase*2)

Sweet potato $\beta$-amylase*3)

$0.2 \mathrm{M}$ Acetate buffer solution ( $\mathrm{pH} \mathrm{4.8)}$

Distilled water

*1) Saccharifying activity, 40 units $/ \mathrm{ml}$.

*2) Dextrinizing activity, 1 unit $/ \mathrm{ml}$.

*3) Saccharifying activity, 10 units $/ \mathrm{ml}$.

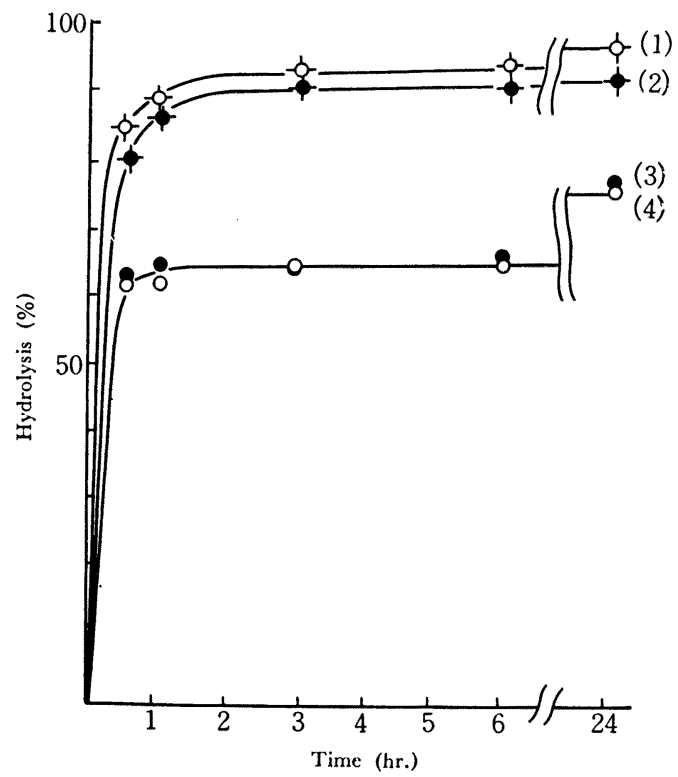

FIG. 4. Hydrolysis of Soluble Starch by Joint Systems of Amyloglucosidase of $E$. sp. and Other Amylases.

Curve $1(O)$, joint action of amyloglucosidase of $E$. sp. and malt $\alpha$-amylase; curve $2(-)$, joint action of amyloglucosidase of $E$. sp. and bacterial $\alpha$-amylase ; curve $3(\bullet)$, joint action of amyloglucosidase of $E$.sp. and sweet potato $\beta$-amylase ; curve $4(O)$, single action of amyloglucosidase of E. sp.. Temperatnre, $30^{\circ} \mathrm{C} ; \mathrm{pH}, 4.8$.

\section{DISCUSSION}

The results of hydrolysis of $\mathrm{C}^{14}$-labeled malto-oligosaccharides with the amyloglucosidase (Fig. 2 and Table V) point to the mode of action same as that reported for amyloglucosidase of Aspergillus niger by Pazur et al. ${ }^{18)}$ : i.e. the hydrolysis begins at the non-reducing end of the molecule and proceeds by a multi-chain mechanism. Chromatograms of the digests of isomaltose and panose show that the amyloglucosidase is capable of hydrolyzing the $a$-D- $(1 \rightarrow 6)$ glucosidic bond as well as the $a-\mathrm{D}-(1 \rightarrow 4)$ bond in the oligosaccharides. As glucose is the only detectable hydrolytic product in the digest of panose (Fig. 3) at all stages, it is suggested that the rate of hydrolysis of $a-\mathrm{D}-(\rightarrow 6)$ bond is lower than that of $a-\mathrm{D}-(1 \rightarrow 4)$ bond. Maltose which would be produced in the slow initial attack of the enzyme on panose is rapidly hydrolyzed to glucose and does not accumulate in the digest. The same results have been reported for amyloglucosidase of Aspergillus niger ${ }^{19)}$.

The hydrolysis of branched substrates such as amylopectin, glycogen and $a, \beta$-limit dextrin to high extents (Tables II and III) prove that the amyloglucosidase has also the ability to hydrolyze $\alpha$-D- $(1 \rightarrow 6)$ bond of higher molecular substrates. These properties are contradictory to the results that starches. were hydrolyzed only to low extents by this enzyme (Table I). On the other hand the amyloglucosidase was not capable of hydrolyzing the linear substrate amylose completely. This may be partially due to the "aging" of amylose, but it seems more probable, as suggested by Baba et al. ${ }^{16)}$, that the macromolecular nature of amylose itself causes the incompleteness of hydrolysis.

Branches in amylopectin linked with $a$-D$(1 \rightarrow 6)$ bonds have been recognized as impediments to the action of $\beta$-amylase on

18) J.H. Pazur and T. Ando, J. Biol. Chem., 234, 1966 (1959).

19) J.H. Pazur and T. Ando, ibid., 235, 297 (1960). 
starch, but in the case of the amyloglucosidase of $E$. sp. it is likely that amylose, linear component of starch, is responsible for the low extent of hydrolysis of starch.

As the partially purified amylase of $E$. sp. hydrolyzed starch almost completely'), it is assumed that some factor which raises the hydrolysis limit of starch is present in the partially purified preparation.

The results of joint action of dextrinizing amylases and the amyloglucosidase suggest that dextrinizing amylase plays an important role in raising the hydrolysis limit of starch with the amyloglucosidase of E. sp. (Fig. 4).
The amyloglucosidase of $E$. sp. is similar to amyloglucosidase of Aspergillus oryzae ${ }^{20}$ ) in various respects: e.g., extent of hydrolysis of starch, ratio of saccharifying amylase activity to maltase activity and ability to decompose $\beta$ - and $\alpha, \beta$-limit dextrins.

Acknowledgement. The authors wish to express their sincere thanks to Prof. Y. Sumiki, Prof. K. Sakaguchi and Dr. S. Iida for their generous guidance throughout the course of this work. The authors are also grateful to Dr. T. Ando for his generous help in carrying out experiments.

20) H. Okazaki, J. Agr. Chem. Soc. Japan, 29, 277 (1955). 